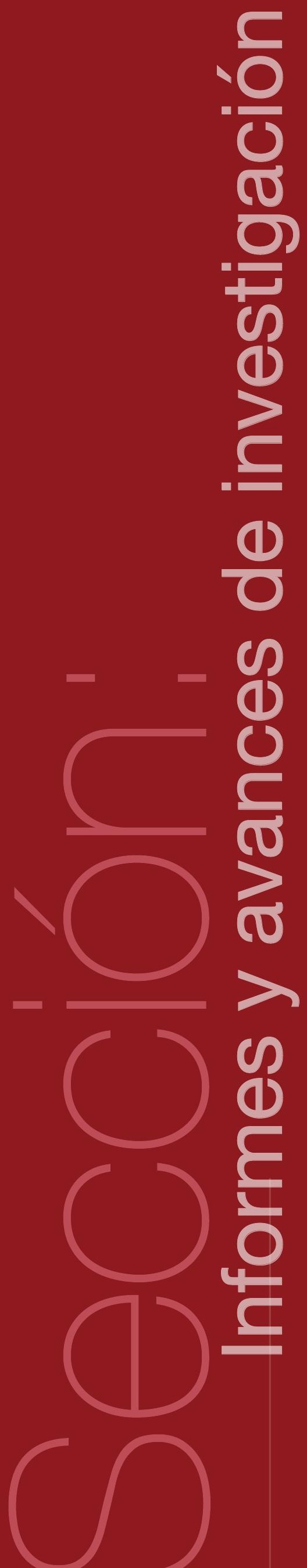




\section{Concepciones de ciudad: saberes previos provocadores de nuevas formas de enseñar la geografía escolar}

Raquel Pulgarín Silva

Claudia María Vélez Venegas

Alberto León Gutiérrez Tamayo

Alejandro Pimienta Betancur ${ }^{1}$

Sonia Maria Vanzella Castellar²

Ante la propuesta de incluir la ciudad como contenido y medio para enseñar significativamente la geografía y las ciencias sociales en la escuela, surgen preguntas sobre ¿cómo se representan los estudiantes la ciudad?, ¿qué saben de ella?, ¿cuál es la importancia que esta tiene para ellos? y en especial ¿que les gustaría aprender de la ciudad?... Interrogantes que se tornan en una excusa para reconocer los saberes previos de los estudiantes, sus necesidades e intereses de conocimiento, pero, sobre todo, en una oportunidad para los docentes de promover la investigación en el aula, la participación activa y el desarrollo de un proceso docente contextualizado.

El reconocer los saberes con los que cuentan los estudiantes al iniciar un proceso de enseñanza posibilita el desarrollo de actividades constructivas que supone aprender un contenido con sentido. Este texto es un acercamiento al análisis de las respuestas obtenidas en el desarrollo del proyecto.

1 Profesores Universidad de Antioquia, Colombia

2 Profesora Universidad de São Paulo, Brasil 


\section{Introducción}

\begin{abstract}
Si la instrucción condiciona el aprendizaje, una forma dominante de enseñar o de instruir provocará la institucionalización de una manera dominante de aprender, creándose un estilo de enseñanza - aprendizaje. Este principio ha sido frecuentemente ignorado.
\end{abstract}

(Gimeno, 2013, p.179)

La mayoría de las investigaciones en el campo de la didáctica se orientan hacia una mejora en la enseñanza, de tal forma que genere aprendizaje. La investigación en la cual se origina este texto es una apuesta por re-significar la enseñanza de la geografía y las ciencias sociales desde el estudio de la ciudad, entendida esta como un territorio, un espacio socialmente construido, un conjunto de lugares, un espacio geográfico donde se dan diversos usos al suelo y cuya característica principal es lo urbano. Ciudad es un concepto en el que se conjugan diversas acepciones del espacio geográfico y en el que se visualizan relaciones e interdependencias de los discursos de las ciencias que se enseñan.

Actualmente, en algunos sistemas educativos del mundo, se avanza en el reconocimiento de la necesidad de construir currículos pertinentes y contextualizados, pero, sobre todo, se está concibiendo un giro en la finalidad de la educación, formar ciudadanos conscientes, reflexivos, críticosy propositivos frente al mundo real que vivimos. Una forma de hacerlo realidad es la apuesta pedagógica y didáctica de enseñar de cara al territorio, o, mejor, estudiar los espacios contemporáneos desde el aula, aquellos espacios habitados donde se ubican las instituciones educativas y, desde una visión interdisciplinaria, donde las ciencias sociales que se enseñan enriquezcan los saberes cotidianos que sobre esos espacios reales tienen los estudiantes y la comunidad educativa en general; pero siempre desde una perspectiva compleja donde lo local y lo global se tejen en significaciones siempre complementarias.

Explorar el conocimiento que el estudiante tiene al emprender un proceso de enseñanza es valorar lo que la pedagogía moderna viene planteando acerca del valor que tiene identificar aquellos saberes con los que llega el estudiante a la escuela; teorías que se ubican en los planteamientos de Karl Popper, cuando critica la analogía de Tabula rasa de Francis Bacon, y señala cómo no somos una tabula rasa recogiendo datos para teorizar después, sino que estamos llenos de prejuicios, expectativas y concepciones (del mundo físico y social) que nos aproximan al mundo de tal forma que siempre estamos conjeturando sobre él $l^{3}$. La enseñanza no puede deshacerse de aquello que el estudiante ya conoce, sino partir de este, como lo destacó David Ausubel al señalar la importancia de los

3 Concepto que es asumido por la Revista Tabula Rasa de la Universidad Colegio Mayor de Cundinamarca, Colombia, como lo señala en su primer editorial en el año 2003. Disponible en: http://www.redalyc.org/articulo.oa?id=39600102 
saberes previos para iniciar un aprendizaje significativo. $Y$ si al proceso docente se le configura desde aquello que el estudiante desea aprender, sería verdaderamente un encuentro para el aprendizaje.

En este trabajo abordamos el análisis de los conocimientos previamente adquiridos por los estudiantes sobre la ciudad ${ }^{4}$, concepto entendido como un espacio concreto, ese mundo real donde viven los estudiantes, el cual se convierte en una meta de la enseñanza de la geografía y las ciencias sociales, y lograrla hace de la comprensión de sus concepciones previas un elemento inicial del proceso.

Respecto a las concepciones, si bien este es un concepto de uso frecuente, no se encuentran resultados de investigación de carácter epistemológico que muestren el origen o las fuentes de su significado; se encuentra utilizado indistintamente como representación, percepción y a veces como preconcepto. De acuerdo con el Diccionario de la Real Academia (2005), la concepción se relaciona con los conceptos de idea y facultad y se define como "formación en la mente de una idea, una opinión o un proyecto". Asimismo, se le entiende como la "representación mental que se tiene de una cosa o asunto".

En una concepción se implican formas de sentir, pensar y actuar frente a algo; de ahí que suele presentarse como sinónimo de representación, visión, actitud y percepción; desde esta última expresión, son diversos los trabajos que se encuentran en el campo de la educación.

Estudiar la ciudad considerando las concepciones de los estudiantes implica conocer las ideas que sobre esta se han creado ellos, ideas que están vinculadas a las experiencias que han tenido y a la información que reciben a través de diversos medios como la televisión, la internet y la prensa, entre otros.

De acuerdo con Fourez (2008), las concepciones se pueden entender como "un modelo espontáneo" (p. 40), el cual toma fuerza o, por el contrario, se desaprende, con la llegada a la escuela y con el abordaje de contenidos relacionados a ese modelo, en el aula de clase. En este sentido, Rodríguez (s.f) señala cómo una concepción es "construida a partir de varios elementos, a saber: el contacto con la enseñanza, con los medios de comunicación y las experiencias de la cotidianidad" (p. 3-4), lo que permite la inserción de nueva información o el cambio de la que se tiene. De ahí que las concepciones se leen como la construcción mental de la realidad, proceso donde la información que llega es codificada, organizada y categorizada dentro del sistema cognitivo de acuerdo a las preocupaciones e intereses del sujeto. Las concepciones, entonces, son dinámicas puesto que cada vez, con la asimilación de nueva información, estas se completan, se mantienen o se transforman.

4 Aunque en el proyecto además del concepto ciudad, se propone indagar sobre las categorías de lugar, urbano y usos del suelo, las cuales no se consideran en este texto, dado que es solo un avance de una investigación que está en ejecución.
Según Giordan, citado por Rodríguez (s.f), "las concepciones se caracterizan por corresponder con una estructura mental subyacente, por ser un modelo explicativo y tener una génesis individual y social". (p. 4). Por ello, al ser un modelo que intenta explicar la realidad, son importantes a la hora de iniciar un proceso de enseñanza, porque, al igual que las representaciones sociales, condicionan la forma de actuar y de entender los espacios, en este caso la forma de entender y de actuar de los estudiantes en la ciudad.

De ahí que en el proceso docente, las concepciones se conviertan en un elemento conector de los contenidos escolares seleccionados, preparados por el docente para el proceso de enseñanza y van a ser mediados por la inclusión de diferentes estrategias didácticas que amplían y recrean esos saberes previos.

\section{El valor del estudio de la ciudad en la educación}

La relación entre ciudad y educación es muy antigua, ya que es en este escenario donde aparece la institución escolar. Pueden observarse a lo largo de la historia dos tendencias educativas: una que desconoce el contexto y otra que trata de integrarse a él. En esta última tendencia se inscriben todas las propuestas que apuestan a reconocer en la ciudad un objeto, un medio y un escenario de educación. Donde la ciudad es más que un espacio geográfico urbano y va de la mano del concepto de ciudadanía.

En este sentido, Moacir Gadotti (2002) señala cómo ciudadano y ciudadanía se derivan de una misma palabra latina civitas: ciudad, la cual es entendida como "una comunidad política cuyos miembros, los ciudadanos, se autogobiernan y el ciudadano es la persona que goza del derecho de ciudad". Esta relación escuela - ciudad - ciudadanía también fue planteada por uno de los filósofos y pedagogos más importantes del siglo xx, John Dewey, (1975) quien establece una necesaria relación de la escuela con el contexto, en una propuesta que se denominó la "Escuela experimental"; en ella pretendía la formación de ciudadanía y, en consecuencia, el fortalecimiento de la democracia. La tendencia en la que se inscribe Dewey es la "pedagogía progresista", que se contrapone a la educación tradicional, entendida como puramente transmisionista. La valoración de la experiencia del niño aparece en ella, así como sus problemáticas asociadas y la búsqueda de soluciones a las mismas. En esa medida, no es posible una enseñanza de espaldas al espacio vivido; por ello, hoy es una necesidad incluir la lectura de la ciudad en el currículo.

En los años 70 la Organización de las Naciones Unidas para la Educación, la Ciencia y la Cultura-UNESCO- publicó el texto de Fauré y otros, "Aprender a ser. La educación del futuro"5, y sus cuatro principios

5 Texto que se verá fortalecido a nivel de orientaciones de políticas públicas con el libro "La educación encierra un tesoro", también producido por la unEsco en 1996. 
básicos: aprender a conocer, aprender a hacer, aprender a ser y aprender a convivir con los demás, y la educación, en todos los escenarios cotidianos, para y durante toda la vida. Todas ellas, propuestas que generan una influencia teórica en las instituciones educativas y dinamizan numerosas experiencias pedagógicas.

En los 70-80, aparecen en el contexto latinoamericano las reflexiones de Paulo Freire en Brasil. Su movimiento, "escuela ciudadana", basado en la concepto de una escuela democrática que permite la transformación social. Es una escuela abierta al entorno, con gran compromiso comunitario que se orienta a la educación popular. Dicha propuesta originó experiencias importantes y en los años 90 dio lugar a una serie de principios orientados a la autonomía, la diversidad cultural y la formación de ciudadanía.

Una de las propuestas más reconocidas en el ámbito internacional es la de "Ciudad educadora". Sus defensores la ven como la posibilidad de potenciar aquellas características educativas que, por su misma dinámica social, son inherentes a la ciudad. Los críticos se refieren a ella como un instrumento de educación cívica, en un sentido oficial. A continuación se presenta una descripción de la evolución de este concepto.

El concepto de ciudad educadora aparece en Barcelona en los años $90 \mathrm{e}$ impulsa un Congreso Internacional de Ciudades Educadoras y, en este, la creación de la Asociación Internacional de Ciudades Educadoras -AICE-. Esta asociación tiene una presencia activa en las ciudades que hacen parte de la organización y ha desarrollado los siguientes congresos:

I. Barcelona (1990): La ciudad educadora para niños y jóvenes

II. Gothenburg (1992): La educación permanente

III. Bolonia (1994): El multiculturalismo, "Reconocerse: para una nueva geografía de las identidades".

IV. Chicago (1996): Las Artes y las Humanidades como agentes de cambio social

V. Jerusalén (1999): Llevar el legado y la historia al futuro

VI. Lisboa (2000): La ciudad, espacio educativo en el nuevo milenio

VII. Tampere (2002): El futuro de la educación. El papel de la ciudad en un mundo globalizado

VIII. Génova (2004): Otra ciudad es posible. El futuro de la ciudad como proyecto colectivo

IX. Lyon (2006): El lugar de las personas en la ciudad

X. São Paulo (2008): La construcción de ciudadanía en ciudades multiculturales

XI. Guadalajara (2010): Deporte, políticas públicas y ciudadanía. Retos de una ciudad educadora

XII. Changwon (República de Corea, 2012): Medio ambiente verde, educación creativa

XIII. Barcelona (2014): La ciudad que incluye
El documento rector de esta propuesta es la "Carta de ciudades educadoras", la cual se fundamenta en la Declaración Universal de Derechos Humanos y otros derechos Económicos, Sociales y Culturales, y pretende un educación para la diversidad, el diálogo intergeneracional, el civismo democrático, favorecer la búsqueda de identidad de las ciudades, la participación ciudadana y una serie de propuestas dirigidas al servicio integral de las personas, entre otros propósitos.

La AICE tiene algunos mecanismos de cooperación entre ciudades como son las redes territoriales y las redes temáticas, y con ellos se busca que las ciudades se ayuden mutuamente en el fortalecimiento de prácticas educativas. Además, tiene un banco donde reposan documentos y registros de experiencias y prácticas al respecto. Algunas experiencias que están consignadas en este banco y que merecen destacarse son:

- Proyecto Andarín, en Portugal, para la preservación y conocimiento de tradiciones culturales

- Clubes de lectura en España

- Proyecto Mancha blanca, en Portugal, que tiene como finalidad la recuperación de espacios públicos deteriorados

- Proyecto La estación del conocimiento, en Brasil, que consiste en ofrecer actividades educativas en un edificio rehabilitado

- Caravana cultural en tu colonia, en Cozumel, México, proyecto que busca la transmisión y valoración de costumbres y tradiciones del lugar

Por su parte, la Organización de Estados Iberoamericanos para la Ciencia la Educación y la Cultura -OIE- ${ }^{6}$ dentro de sus políticas culturales tiene como principios la promoción y protección de la diversidad cultural, el fomento de la creatividad y la participación ciudadana, promueve además una serie de actividades, proyectos y publicaciones que se cruzan con los ideales de Ciudad educadora.

Algunas experiencias de trabajo con Ciudad educadora en Colombia se encuentran en: Bogotá y Tabio (Cundinamarca), Medellín, Envigado, Sabaneta, Itagüí y Guatapé (Antioquia); Cartagena (Bolívar); Manizales (Caldas) y Armenia (Quindío).

Como puede observarse, la ciudad viene siendo pensada como una posibilidad de fortalecer la formación ciudadana desde proyectos políticos de ciudad. En el caso de ciudades como Medellín, la relación ciudad-educación ha avanzado desde la inclusión de las escuelas, en el proceso docente de las ciencias sociales en particular, a través del desarrollo de diversas estrategias como "salidas que enseñan ciudad", "el museo, un aula", entre otras, desde las cuales se dinamiza el reconocimiento y el uso de los diferentes espacios culturales, deportivos y recreativos en la ciudad.

6 Texto que se verá fortalecido a nivel de orientaciones de políticas públicas con el libro "La educación encierra un tesoro", también producido por la UNESCO en 1996. 
El estudio de la ciudad en clave pedagógica y didáctica va a la par con la finalidad de la educación: lograr la formación ciudadana. Posturas y conceptos que toman fuerza en los últimos años y hacen parte de los objetivos de gran cantidad de proyectos y campañas educativas y políticas. Pimienta (2012) habla, incluso, de una "naturalización" del término formación ciudadana.

Unidas a esta tendencia están las prácticas educativas asociadas al estudio de la ciudad, las cuales han ganado un espacio importante en el ámbito educativo a nivel global y local. Como pudo evidenciarse, experiencias que se han venido desarrollando y que asumen como premisa teórica la construcción de ciudadanía como elemento importante de las transformaciones sociales. Sin embargo, muchas veces estos marcos teóricos de los estudios y prácticas se asumen relacionados como un deber ser o un lugar a donde se llega, y no se analiza el punto de partida que es, siempre, el saber previo del sujeto que aprende. Desde la teoría constructivista, el saber previo es el que permite al sujeto reconstruir nuevos significados sobre la base de aquellos que tenía antes y que constituyen el "soporte" para nuevos conocimientos.

\section{Concepciones sobre la importancia de las ciencias sociales}

Es este un primer acercamiento al estudio de las concepciones de ciudad, en los estudiantes de sexto grado, alcanzado mediante la información obtenida a través de un cuestionario donde se buscó, además de la caracterización sociodemográfica, conocer sus opiniones sobre las ciencias sociales como área de enseñanza y sobre la presencia de los contenidos sobre ciudad en el proceso docente. Se obtuvo que los estudiantes otorgan importancia a las ciencias sociales que estudian, en función de: sus afectos y desafectos hacia quien les enseña, a las metodologías privilegiadas en el desarrollo de las clases, al valor formativo del área y a los temas o contenidos abordados en los encuentros de clase. Inferencias que se dan desde los hallazgos obtenidos en el cuestionario aplicado a 651 estudiantes del grado sexto, en la ciudad de Medellín, niños cuyas edades oscilan entre los 10 y 16 años, y 372 de ellos son del género femenino.

\section{El docente como referente de la importancia del área}

Las ciencias sociales que se enseñan, de acuerdo a la mayoría de los estudiantes encuestados, un $70 \%$ de ellos, son consideradas un área interesante, y como razones exponen el que "el docente es agradable, los trata bien, es divertido en el desarrollo de las clases, son encuentros entretenidos, es un espacio donde se comparte con los compañeros, les explica muy bien los temas, les permite que ellos pregunten y se abordan situaciones de la vida diaria permitiéndoles su participación en el desarrollo de las clases".
En estas afirmaciones se puede reconocer cómo el docente sigue siendo protagonista en el proceso docente que lidera y, sobre todo, puede constituirse, o no, en un provocador de deseos de aprender en los estudiantes, $y$, por qué no, ser quien logra la disponibilidad del estudiante para el aprendizaje.

\section{El valor de los temas o contenidos que se enseñan}

Esta es quizá la tendencia más común en las respuestas de los encuestados, al destacar la pertinencia de la información o de los contenidos que se ofrecen. Entre las razones dadas sobre la importancia de las ciencias sociales, los estudiantes señalan el "valor que tiene estudiar los países, hablar de política y hacer mapas". Asimismo, fueron respuestas muy frecuentes las relacionadas con el agrado hacia los contenidos sobre la ciudad y el barrio en el cual viven, su complacencia por los temas relacionados con los planetas, las regiones del mundo, las grandes ciudades y los problemas que en ellas se dan; además, se señala en especial el uso de los videos e imágenes que en las clases el profesor les ofrece.

Algunos estudiantes también ubican la importancia de esta área en la posibilidad de "hablar sobre el campo y la ciudad, sobre las montañas, los ríos y los mares", pero también sobre "las diferentes culturas que existen en el mundo". Es destacable el número de respuestas alusivas al valor de "conversar sobre la política, el gobierno y las guerras" que históricamente se han dado en los pueblos. Inclusive, por todo ello, algunos la consideran como su área preferida en el marco de las áreas en su plan de estudios.

\section{El valor del área en su formación personal}

El análisis del contenido de las respuestas evidenció un gran énfasis en el papel de las ciencias sociales en la formación como personas integrales, al afirmar que estas "enseñan sobre nosotros mismos y sobre la vida cotidiana, permitiéndonos entender la vida y lograr nuestros sueños, nos enseñan a ser mejores personas desde el aprendizaje de hábitos de convivencia y el reconocimiento de nuestro papel en la sociedad".

Es destacable el que la mayoría de los estudiantes se haya apropiado de la finalidad formativa del área; podría pensarse en la estrategia de motivación desarrollada por los docentes en el comienzo del año escolar?

\section{Las formas prácticas en la enseñanza de las sociales}

Otra perspectiva identificada en las respuestas sobre la importancia de las ciencias sociales escolares se ubica en las metodologías empleadas en el proceso docente; en particular, los estudiantes reconocen como

7 Dado que este cuestionario se aplicó en los meses de febrero y marzo en las cinco IE participantes en el proyecto de investigación, momento en el que tiene lugar la presentación del curso ante los grupos. 
factores de gran importancia de esta área las explicaciones claras ofrecidas por parte del docente, el trabajo en equipo, el uso de recursos didácticos como los mapas, la técnica de las preguntas sobre diversos temas de actualidad que los llevan a la búsqueda de información y, de manera especial, se indica cómo se vuelve una materia fácil por la participación del grupo en el desarrollo de los temas.

Igualmente hay quienes consideran que las ciencias sociales no son importantes, un 30\% del grupo encuestado así lo señala y expresa como razones el que "el docente regaña mucho, explica poco, es muy duro con las evaluaciones, los hace escribir demasiado" y, en especial, señalan cómo los "temas que se estudian son difíciles de entender y muy aburridos". Asimismo, explican su desagrado frente a esta área o el que no les gusta, debido a que "no le entienden nada al profesor, encuentran los temas y sus explicaciones aburridas, son muy informativas, se incluye demasiada política en las clases y se presentan teorías largas e incomprensibles".

Vale anotar que los estudiantes del sexto grado de las IE participantes en Medellín deben enfrentar grandes dificultades diariamente, pues estas instituciones se asientan en barrios con problemáticas sociales importantes, y esto se refleja en la escuela. Las IE participantes están bien distribuidas en el territorio municipal, el cual está organizado en zonas, comunas y barrios. De un total de 16 comunas, tenemos IE en la Comuna 1: Popular; Comuna 3: Manrique; Comuna 5: Castilla, y en la Comuna 15: Guayabal. En el siguiente mapa se presenta la ubicación de las instituciones educativas participantes en el proyecto de investigación.

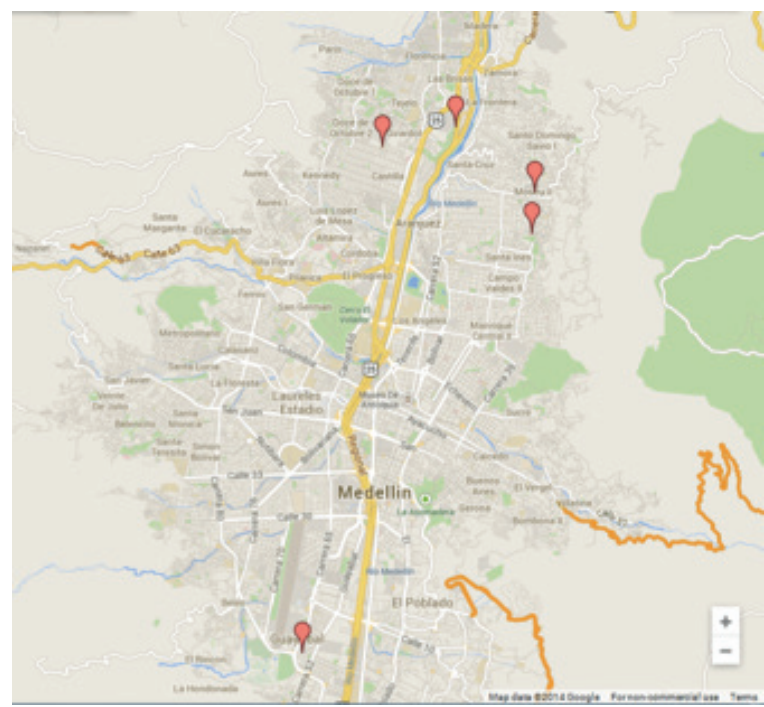

Aunque cada una de las comunas de Medellín tiene sus particularidades, son condiciones comunes de estos territorios el bajo nivel socioeconómico de sus pobladores y la presencia de problemáticas asociadas al desempleo y la violencia.

Fuente: Google Earth, noviembre de 2013.
Con este panorama, nuestros docentes y niños tienen que sobreponerse a la realidad y construir con empeño su proyecto educativo. Características que de cierta manera van a incidir en su conocimiento sobre la ciudad, en las concepciones que de ella tienen, puesto que la experiencia misma de los lugares está determinada en gran parte por sus recorridos cotidianos, y su conocimiento de espacios por fuera del entorno inmediato es bastante limitado puesto que casi el $100 \%$ de los estudiantes encuestados no tienen que pasar por el centro de la ciudad para ir a su institución, y su relación con este entorno está dada por la escasa experiencia de ir al centro y, sobre todo, por los ejercicios realizados en la escuela, ya que la mayoría admite que la ciudad, el barrio u otros lugares han sido objeto de estudio en el aula.

\section{Saberes de los estudiantes sobre la ciudad}

En la información ofrecida por los estudiantes sobre aquello que les gustaría estudiar o aprender sobre la ciudad, se identifican más preguntas que afirmaciones, $y$, como es sabido, para preguntarse es necesario saber algo previamente sobre lo cuestionado, pues de lo contrario no sería posible interrogarse. De ahí que las sugerencias o, mejor, solicitudes que los estudiantes hacen sobre lo que desean estudiar sobre la ciudad puedan leerse como aquellas referencias a lo que de cierta manera han estudiado y sobre lo que desean ampliar su conocimiento.

La mayor preferencia de los estudiantes sobre qué estudiar acerca de la ciudad se ubica en el reconocimiento de los lugares más destacados o importantes para ellos; al respecto, expresan el deseo de saber sobre: "el Parque Berrío, los museos, el Parque Zoológico, las Empresas Públicas, el Planetario, el estadio, el Parque de las Aguas, el Jardín Botánico y por aquellos lugares más hermosos que hay en la ciudad de Medellín". Igualmente se preguntan por las iglesias que son patrimonio, por el Metro de Medellín, el Metro Cable, el Metro Plus, el Parque Explora, la Universidad de Antioquia y la Plaza Botero; también expresan el deseo de saber sobre lugares especiales de ciudad para hacer deporte, por los lugares más reconocidos por su cultura, por las bibliotecas que hay en la ciudad, los parques recreativos y los lugares más turísticos.

En sus respuestas hay una fuerte presencia de la necesidad de estudiar los barrios de la ciudad, sus diferentes sectores, las zonas en las que está organizada Medellín y cómo se clasifican; desean saber sobre el entorno de los barrios y comunas, se preguntan por la historia de las carreras y calles. También señalan el deseo de estudiar los lugares más cercanos a su colegio o instituciones educativas, y manifiestan el deseo de saber sobre otros colegios, acerca de las canchas deportivas donde puedan ir a jugar, reconocer los almacenes grandes, los parques de diversión y los centros comerciales. 
Se identifica una fuerte tendencia hacia los contenidos históricos sobre la ciudad, cuando ellos muestran el deseo de conocer más sobre "cómo se creó la ciudad, cómo fue fundada y cómo fue avanzando, saber acerca de todo lo que pasó en los años anteriores cuando nuestros abuelos todavía eran niños, conocer acerca de la historia de los ancestros que marcaron alguna huella; conocer de aquellos personajes de Medellín que se recuerdan más; saber cómo eran las calles, los barrios, las fiestas que disfrutaban antes en Medellín; reconocer el arte en años pasados, la historia actual de las comunas, en general, saber las historias de la ciudad".

Otros contenidos señalados con frecuencia en las respuestas de los estudiantes se relacionan con la necesidad de saber acerca del centro de la ciudad, identificar por qué es tan importante, cómo se convirtió en organizador de la ciudad, así como las diferencias del centro de la ciudad con los demás barrios y, en especial, esperan aprender a ubicarse en la ciudad y aprender a moverse por ella sin perderse; en este sentido, señalan cómo recorrer la ciudad es muy necesario y lo relacionan con la elaboración de mapas y con el deseo de caminar por sus barrios "haciendo croquis".

Algunos estudiantes hicieron alusión a la necesidad de incluir contenidos sobre "la economía de mi ciudad, que se enseñe la historia de la agricultura y por qué no la hay actualmente en Medellín, por qué no se cultivan alimentos en la ciudad"; desean conocer sobre las comidas, el transporte y las condiciones de la movilidad en sus barrios. Asimismo, se preguntan sobre las empresas más importantes y su funcionamiento. Quieren conocer acerca de las tecnologías nuevas que hay en la ciudad, sobre los edificios más destacados. Inclusive, hubo quienes expresaron el deseo de saber sobre la ingeniería de objetos o cosas y sobre los cambios de la arquitectura en la ciudad; en general, quieren saber sobre cómo vive la gente en la ciudad.

Hay una tendencia muy destacada entre los estudiantes que desean aprender sobre el entorno geofísico y ambiental de la ciudad; en especial, quieren "saber sobre el río de Medellín o si hay otros ríos y fuentes de agua que recorran la ciudad", se preguntan sobre las "zonas rurales" o "zonas verdes", como también las nombran. Sobre "los parques ecológicos, acerca del por qué se forma la neblina siempre en la ciudad". Desean conocer sobre las montañas que rodean a Medellín y se preguntan sobre qué hay detrás de ellas. El agua de la ciudad es otra preocupación sobre la que los estudiantes quisieran conocer más. Asimismo, existe el deseo de saber y diferenciar los lugares y paisajes diferentes y en los que hay "mayor naturaleza". Se preguntan sobre las cosas que nos rodean y saber quién las transforma; por ejemplo, quisieran saber "cómo están hoy las cañadas en la ciudad"; desean conocer acerca de los tipos de flores, cómo y dónde se producen. También manifiestan la aspiración de saber cómo superar el problema de las basuras en el colegio.
Otras sugerencias de qué estudiar sobre la ciudad se refieren a "comparar la ciudad de Medellín con todas las ciudades vecinas que no conocemos", a comprender mejor lo que es el Metro, el mecanismo y el funcionamiento del Metro cable, y qué es eso de "la cultura metro", puesto que este es el medio de transporte más importante. Expresan de manera reiterada la necesidad de diferenciar todos los barrios, de reconocer en ellos todas sus escuelas, saber por dónde pasa el metro, saber por qué tenemos este paisaje estupendo que hace a la ciudad muy hermosa y cuáles son los lugares donde uno se puede divertir y disfrutar más.

Es destacable la frecuencia de contenidos sociales o sociológicos considerados como importantes de estudiar sobre la ciudad de Medellín; por ejemplo, expresan el deseo de saber "por qué hay tanta pobreza entre nosotros", quieren estudiar "las características de cada uno de sus barrios, saber cómo es su gobierno", reconocer "las características principales de la ciudad, tanto las cosas malas, puesto que Medellín no es solo una ciudad de maravillas". Quieren saber por qué hay tanta violencia, tanta delincuencia, estudiar por qué la gente se viene de otros pueblos para Medellín. En general, manifiestan el deseo de saber el cómo vivir mejor, aprender métodos para andar por las calles con seguridad, quieren entender qué está pasando en la ciudad. Otros, por su parte, manifiestan que quieren aprender sobre "cómo mantenerla limpia y organizada, aprender a cuidar todo lo que hay en la ciudad, cómo ser tolerantes y reconocer los lugares donde no roban".

Otro aspecto igualmente muy reiterado en las respuestas de los estudiantes es la aspiración de conocer sobre la cultura de la ciudad. Al respecto, manifiestan interés por identificar los personajes de Medellín, saber sobre los escritores más importantes y acerca de la música que se produce en la ciudad; asimismo, se preguntan por las actividades que se realizan en otros lugares, desean "conocer otras instituciones como la nuestra, reconocer la política de la ciudad y de los gobiernos frente a las diferentes comunas". También se preguntan sobre "qué nos hace diferentes de otras comunas, si todos estamos viviendo lo mismo", quieren saber sobre "cómo podemos cuidar más nuestra ciudad". Manifiestan el deseo de saber más sobre las diferencias de lo urbano y sobre el civismo y acerca de cómo ayudar al cambio en nuestra ciudad. Un buen número de los estudiantes esperan saber "cómo cambiar a las personas para que sean buenas y amistosas, que no necesiten robar". Incluso, hay estudiantes que directamente y de manera genérica nombran el deseo de saber sobre la cultura, la geografía y la historia de Medellín.

Finalmente, hay que reconocer que un $10 \%$ de los estudiantes encuestados no se ubicó en la pregunta y expresó su deseo de estudiar sobre la ciudad asuntos o temas que están fuera del área, como "aprender más sobre las células y sus partes, sobre el cuerpo humano, sobre la vida salvaje, hacer experimentos de biología, las partes del animal, las calles de 
nuestro país", o afirman, no desear saber "nada, pues ya me lo enseñaron", o querer saber "todo, porque casi no la conozco" (sic), lo cual es una vaciedad y es también una ausencia de preguntas, que anuncia que hay mucho por descubrir y provocar a los estudiantes el deseo de aprender sobre el lugar donde viven. Estas respuestas también pueden significar que no hubo comprensión de la pregunta o una actitud indiferente frente a la actividad realizada con este cuestionario.

Las necesidades de conocimiento expresadas por los estudiantes y resumidas previamente permiten inferir cómo sus intereses de conocimiento se ubican en estudiar las problemáticas de la ciudad, sus preocupaciones van en relación con la realidad que ellos viven, desean estudiar a Medellín desde todas las perspectivas, ambiental, histórica, cultural, social, política, etc. Demandan conocer su ciudad a partir de su barrio, muestran preocupación por los problemas sociales y ambientales que en la ciudad se dan, con lo cual están haciendo un llamado a leer el contexto, a reconocer el mundo real y desde la enseñanza apostarle a develar el mundo de la vida.

Son muchos los lugares o espacios concretos de la ciudad referenciados por los estudiantes como importantes y que desean conocer mejor, lugares que en buena parte coinciden con aquellos que se han convertido en símbolos en la ciudad, espacios promotores de cultura que son referentes de la ciudad o que han sido ampliamente publicitados en los proyectos políticos de los últimos gobernantes. Igualmente llama la atención la frecuencia en las respuestas del deseo de conocer el centro y valorar las diferencias de este con respecto a los barrios, lo cual orienta de cierta manera la concepción de ciudad. Este desconocimiento del centro, espacio representativo de la ciudad, preocupa, puesto que, como lo señala Lefrevbre (1978), el derecho a la ciudad es el derecho a la centralidad, tratando de explicar que es en esta, la centralidad, donde básicamente se adquiere la noción de ciudad y de ciudadanía.

El conocimiento de la ciudad, desde sus demandas o sugerencias de lo que quieren estudiar, revela un conocimiento muy escaso de la ciudad, no la conocen desde la experiencia misma ni tampoco desde los temas o contenidos escolares ofrecidos desde el currículo, pero sí anhelan conocerla desde los diferentes ámbitos o dimensiones del espacio geográfico. Se preguntan sobre cómo está organizada la ciudad (territorio), cómo ha cambiado su apariencia con el tiempo (paisaje), qué la caracteriza como medio geográfico que ofrece recursos para la economía, etc. Todo ello es una oportunidad para abordar el estudio de ciudad como un concepto inter y transdisciplinario, donde entran en relación otros conceptos como urbano y lugar, que también hacen parte de nuestra búsqueda investigativa y forman un entramado que permitirá formar una red para la formulación de nuevas propuestas didácticas.

\section{Propuestas didácticas que permitan el encuentro de saberes sobre la ciudad}

El reconocimiento de aquello que los estudiantes desean saber sobre la ciudad debe ser un indicador o un principio a la hora de pensar en la organización del proceso docente de la geografía y las ciencias sociales. Estas necesidades de conocimiento permiten leer el nivel de los saberes con los cuales los estudiantes llegan al momento de emprender un estudio de la ciudad, pero también son un indicador de un posible temario para construir desde el plan integrado de área -PIA-y del proyecto de aula que cada docente elabora para el año escolar y que se ajusta según el grupo de estudiantes con quien lo desarrolle; de ahí que el proyecto de aula sea la organización microcurricular que se lidera en cada curso. Esta ha de ser una propuesta que favorezca y potencie la concepción espacial del estudiante, como lo señala Castellar (2011), que permita el conocimiento del territorio, su identidad hacia los lugares, además de la comprensión de su país, mediante la significación de su contexto sociocultural.

Desde las preguntas identificadas en los estudiantes se puede proponer el estudio de la ciudad como:

- Un conjunto de lugares dotados de valor desde las experiencias mismas del sujeto, lugares especiales para la cultura, el deporte, el arte, las ciencias, etc.

- Un geosistema donde se conjugan contenidos acerca el sustrato geofísico (el suelo, los ríos, las montañas, etc.), sobre el cual se soporta la cultura de los pueblos que lo habitan, se desarrolla la economía y demás actividades que soportan la vida de la gente y en que se presentan problemáticas ambientales que ameritan su comprensión.

- Un paisaje dinámico y cambiante desde las diversas obras de infraestructura que en ella se dan cada día, y donde se expresan imágenes y apariencias diversas del espacio construido.

- Un territorio que es ordenado, administrado políticamente y en el que se diferencian diversidad de culturas $y$, con ellas, diferentes problemáticas sociales.

Un temario que, como lo señalan Fernández y Gurevich (2007), enfatizará en la fundamentación conceptual y el abordaje de problemáticas territoriales, donde se incluyan diversos contenidos básicos de la geografía en sus diferentes tendencias y perspectivas teóricas, las cuales acercan las dimensiones naturales y sociales del espacio geográfico.

Temáticas que facilitan entender la ciudad como un espacio geográfico que va más allá de fragmentos del territorio, es decir, favorecer en el estudiante el establecimiento de relaciones entre lo más particular con escalas de análisis espacial un poco más amplias (el sector, el barrio, la comuna, la ciudad, etc.), tal como lo plantean Alderoqui (2003) y Gurevich (2005). 
El estudio de la ciudad hace posible espacializar las relaciones sociales en su más íntima esencia social e histórica; como lo expresa Gutiérrez (2012), la ciudad es producto y obra del hombre, lo cual incorpora a su evolución el movimiento propio de la vida humana, el dinamismo de la sociedad. No es solo el mundo de las cosas, de los objetos, de lo material que se percibe a simple vista; es, también, la expresión del complejo, tenso y conflictivo proceso de producción de la humanidad basado en la formación espacial, económica y social y, al tiempo, las múltiples y diversas maneras de vivir, anhelar, habitar, sentir y soñar que conjugan ideas, representaciones, simbologías, comportamientos e interrelaciones con otros, que revelan y hacen visibles la inconmensurabilidad de los propósitos humanos, sus variadas visiones, contradictorios e inalcanzable intereses, las multicolores realidades y fragmentadas cosmologías. Objetos localizados espacialmente y construcción social hacen de la ciudad algo no acabado, indefinido, cambiante, en construcción permanente, en medio de conflictos y tensiones marcadas por su devenir histórico, por las formas que la perfilan, los elementos que la caracterizan y la distintas funciones que asume.

Lo anterior igualmente nos lleva a pensar en estrategias didácticas que faciliten el desarrollo de las temáticas propuestas. Por ejemplo, ante la preferencia de los estudiantes por ciertos lugares que no conocen, se ve la pertinencia de los itinerarios urbanos y las salidas de campo, apoyadas en la análisis de textos, el levantamiento de mapas mentales y la lectura de mapas geográficos o cartogramas de la ciudad, que faciliten el aprender a orientarse en el espacio de la ciudad y a reconocerse como parte de ella.

El uso de las tecnologías de la información y la comunicación como la internet, y con ella las diferentes herramientas web 2.0, facilita el estudio de la ciudad, como expresa Jaramillo (2014). Herramientas como el sitio Facebook, la Wikimapia, (mapa interactivo editable), Google Maps (servicio gratuito de Google), Google Earth (información geográfica de todo el mundo), Youtube (sitio web que funciona como repositorio de videos), entre otros, se convierten en medios que permiten el acercamiento a información actualizada y diversa de la ciudad, además de otras formas de aprender en línea, con los otros y desde los otros.

En general, se pueden recrear las estrategias convencionales de enseñar, a partir de la combinación de los saberes del estudiante con la información que circula en los medios de comunicación (en especial la internet), con los contenidos escolares seleccionados y planeados por el docente para ser enseñados significativamente, es decir, con la intencionalidad de que sean aprendidos. Por ello, dichas estrategias se ubican en una didáctica socioconstructivista, donde la enseñanza es entendida como un proceso dinámico de construcción de conocimientos, lo cual implica, de acuerdo con Fourez (2008), una organización de la enseñanza desde la perspectiva del sujeto que aprende; en otras palabras, en ella cuentan sus necesidades e intereses de conocimiento, hay una disposición para la interacción entre pares (se crea un clima de diálogo entre el docente y los estudiantes) y se incluyen los elementos contextuales al desarrollo del conocimiento.

\section{Reflexión a modo de cierre}

Abordar el estudio de la ciudad con intencionalidad pedagógica y desde aquello que los estudiantes saben y piensan sobre ella es hacer de la ciudad una excusa para comprenderla como ese lugar del cambio histórico, un lugar en el que se puede contemplar el mundo con la esperanza de producir un futuro, como señaló Milton Santos (2002), "un lugar donde reside una humanidad mixturada y donde se leen los problemas sustantivos de la realidad". Una ciudad desde la cual se puede hablar también de la nación y del mundo, en la medida en que constituye, en cualquier escala de observación, el mejor revelador de situaciones, no solo coyunturales, sino estructurales y de crisis.

Las concepciones, ideas o saberes previos de los estudiantes sobre la ciudad deben ser la base en la construcción de los temas o contenidos para trabajar en los proyectos de aula. Solo así podemos seguir en la búsqueda del sentido de la educación, pues, como lo afirma el maestro Gimeno Sacristán, "hemos hecho de la educación una esperanza de progreso universal a la que no podemos renunciar". Y si lo afrontamos desde una perspectiva socioconstructivista, hemos de hacer énfasis en la participación activa de los protagonistas del proceso docente: el profesor, quien facilita y estimula activamente el desarrollo de los procesos de investigación en el aula, y el estudiante, quien se compromete a indagary comprender aquello que amerita comprenderse sobre su espacio vivido, en busca de soluciones a los problemas que en él se dan. 


\section{Referencias bibliográficas}

Alderoqui S. (2003, junio). La ciudad: Un territorio que educa. Cuaderno CRH, Salvador, N. 38, p. 153-176. Disponible en: http://goo.gl/Jwrtb.

Araya, S. (2002). "Las representaciones sociales: ejes teóricos para su discusión". Cuaderno de ciencias sociales n. ${ }^{\circ} 127$. Costa Rica: FLACSO. Disponible en internet: http://www.flacso. or.cr/index.php/publicaciones-jb-br-jb-i-labor-editorial-jb-i/ cuadernos/336-cuaderno-no-127.

Castellar, S. (2011). "La superación de los límites para una educación geográfica significativa: un estudio sobre la ciudad y en la ciudad". Revista Anekumene n. ${ }^{\circ} 1$. Revista virtual.

Dewey, J. (1975). Democracia y educación. Madrid: Morata S. L.

Diccionario Real Academia Española y Asociación de Academias de la Lengua Española. (2005). 1. ${ }^{a}$ edición. Madrid: Santillana.

Diccionario Enciclopédico Vox 1. (2009) Larousse, S. L.

Donzelot, J. (2012). Hacia una ciudadanía urbana. La ciudad y la igualdad de oportunidades. Buenos Aires: Nueva Visión.

Faure, Edgar et al. (1973). "Aprender a ser. La educación del futuro". Alianza/ UNESCO. En: http://unesdoc.unesco.org/images/ 0013/001329/132984s.pdf.

Fernández, M., Gurevich, R. (coord.) (2007). Nuevos temas, nuevas preguntas Un temario para su enseñanza. Buenos Aires: Biblios.

Fourez, G. (2008). Cómo se elabora el conocimiento. La epistemología desde un enfoque constructivista. Madrid: Narcea S. A.

Gadotti, M. (2002). "Escuela ciudadana, ciudad educadora. Proyectos y prácticas en proceso". Primera Conferencia Internacional de educación, Riberao Preto San Pablo, Brasil. Traducción del portugués al castellano de Jorge R. Seibold, S. J.

Gurevich, R. (2005). Sociedades y territorios en tiempos contemporáneos: una introducción a la enseñanza de la geografía. Buenos Aires: Fondo de Cultura Económica.

Gutiérrez (2012). “Formación ciudadana en perspectiva del potencial pedagógico de los estudios de territorio ciudadano territorial: fundamento de la democracia". Tesis para optar al título de Doctor en Educación. Facultad de Educación: Universidad de Antioquia.

Jaramillo, Y. (2014). "Enseñanza de la geografía desde el estudio de territorios urbanos mediada por aplicaciones web 2.0." Tesis de maestría. Universidad de Antioquia. En formato Pdf. 
Lefebvre, H. (1978). El derecho a la ciudad. Barcelona: Península.

Pimienta, A. (2012). "Formación ciudadana, proyecto político y territorio". Tesis para optar al título de Doctor en Educación. Facultad de Educación: Universidad de Antioquia.

Pulgarín, R. \& Castellar, S. (2012). “Estudio comparado sobre las concepciones de lugar, ciudad, urbanoy usos del suelo con profesores y estudiantes de San Pablo-Brasil y Medellín-Colombia". Proyecto de investigación presentado a la convocatoria COLCIENCIAS-Colombia n. ${ }^{\circ} 597$ de 2012 y, al edital CAPES-Brasil n. ${ }^{\circ} 048$ de 2012.

Restrepo, G. \& Vélez, C. (2007). Sabaneta: ciudad educadora 199-2007. Documento de Sistematización de la experiencia. En Pdf.

Rodríguez, E. (sf). Concepciones de práctica pedagógica. Grupo de Práctica Pedagógica del Departamento de Ciencias Sociales. Universidad Pedagógica Nacional. En: http://www.pedagogica.edu.co/ storage/folios/articulos/fol16_11inve.pdf

Rue, J. (1996, diciembre). “Concepciones y prácticas”. Cuadernos de Pedagogía n. ${ }^{\circ}$ 253. Barcelona: R.B.A.

Sacristán, J. (2013). En busca del sentido de la educación. Madrid: Morata S. L.

Santos, M. (2000). Naturaleza del espacio. Técnica y tiempo, razón y emoción. Barcelona: Ariel.

Santos, M. (2002). "O país distorcido: o Brasil, a globalização e a cidadania”. (“Un país desvirtuado: Brasil, globalización y ciudadanía”). Publifolha, São Paulo. Traducción de Delfina Trinca Fighera. Revista Geográfica Venezolana, vol. 43 (2), p. 331-334.

Sierra, Y. (2014). "Concepciones y representaciones sociales de la ciudad: componentes de una propuesta didáctica en la enseñanza de la geografía". Tesis de maestría. Universidad de Antioquia.

Trilla, J. (1990) Introducción al documento "La ciudad educadora". Ayuntamiento de Barcelona. I Congreso. Internacional de Ciudades Educadoras. p 19. Citado Por Cabezudo, A. Ciudad educadora, una manera de aprender a vivir juntos. En: http://www.hegoa. ehu.es/congreso/gasteiz/doku/Ciueduc.pdf.

Villa M., Marta I. \& Moncada, R. (1998). Ciudad educadora en Colombia. Medellín: Corporación Región. 